\title{
Un esquema de análisis para el estudio de los partidos políticos en procesos de transición: fundación frente a tradición ${ }^{1}$
}

\section{Manuel Alcántara}

Universidad de Salamanca. Instituto de Estudios de Iberoamérica y Portugal.

Torre de Abrantes. 37001 Salamanca. Spain

Fax: (923) 294637

MaLCANTA@GUgU.USAL.es

Fecha de recepcion: marzo de 1994

\section{Resumen}

Se presenta, en primer lugar, un modelo para analizar el papel de los partidos en las transiciones, diseñándose el alcance del concepto de "vigor partidista" en un entramado en el que también ocupan un eje explicativo el nivel de movilización y el tipo de institucionalización. Posteriormente, este modelo es aplicado al caso centroamericano presentándose un esquema partidista dual, conformado por el peso de la fundación, que riene plena vigencia en El Salvador, Guazemala y Nicaragua, y de la tradición, adscrito a Costa Rica y Honduras.

Palabras clave: partidos políticos, sistemas de partidos, transiciones democráticas, Centroamérica.

Abstract. A framework for the study of political parties in transitions: foundation vs, tradition

The article discusses the party systems that are emerging in the Central American countries. Two main groups of countries are described: In Costa Rica and Honduras the rraditional party systems have changed little during the eightics, whereas in Guatemala, Nicaragua and El Salvador the political parties that have appeared after the 1980 s wars are remarkably different that those existing in the pre-revolutionary crisis. This situation is analyzed related to the tole that political parties play in democratic transitions, and the traditional weakness of political parties in the newly democtatized countries.

Key words: political parties, political parties systems, democratic transitions, Central America.

\section{Sumario}

$\begin{aligned} \text { 1. Los partidos en } & \text { 3. Eṕlogo } \\ \text { las transiciones politicas } & \text { Bibliografia } \\ \text { 2. Consideraciones para } & \\ \text { el caso centroamericano } & \end{aligned}$

1. La parte central de las ideas aqui presentadas originalmente fueron debatidas en el Seminario internacional "El fin de siglo y los partidos políticos en América Latina", celebrado en el Instituto de Investigaciones Dr. José María Luis Mora. México, del 24 al 26 de noviembre de 1993. 
En la presente ponencia se traslada un modelo de análisis para el estudio de las transiciones al universo de los partidos políticos. De esta suerte, en su primera parte se ponen de relieve los aspectos más significativos que concurren en la formación y en las características de los partidos resultantes del proceso transicional, lo cual permite la realización de tipologías. Aplicado este modelo, en la segunda parte, para el caso de los países de América Central, puede inferirse la existencia de dos tipos de sistemas de partidos en la subregión: uno consistente en la fundación y otro en la tradición.

\section{Los partidos en las transiciones políticas}

En un anterior trabajo (Alcántara, 1992) se ha defendido la aplicación de un modelo para el análisis de las transiciones políticas que debe contemplar cuatro elementos básicos desde un punto de vista estrictamente formal. Se refieren a las características del régimen político anterior; a la justificación de la crisis que condujo a la quiebra de los regímenes no democráticos; a la estrategia seguida en el proceso del cambio, y a las características del nuevo régimen establecido una vez que hubieran sido formuladas y aceptadas por la mayoría reglas políticas funcionales y definitivas, distintas a las vigentes en el periodo no democrático.

Este modelo puede también aplicarse desde la perspectiva de su repercusión en la conformación de un determinado sistema de partidos o de unas actitudes que, posteriormente, gravitarán en la puesta en marcha de uno bajo el sistema democrático. Una aproximación según estas líneas de estudio es particularmente atractiva en aquellos casos, como el centroamericano, donde la institucionalidad partidista estuvo escasamente presente a lo largo de su historia.

\section{a) El legado politico previo}

De esta forma, el primer elemento tiene en cuenta la historia política en lo atinente a la movilización política, tanto durante el último referente de régimen democrático, en el caso de que éste hubiese existido, como a lo largo del régimen político inmediatamente anterior.

En el primero de estos escenarios se sitúan los países objeto de estudio sobre un eje deffnido por el "vigor partidista", de suerte que aquellos que alcanzan un grado máximo se ubican en un extremo del mismo y los que tienen un nivel mínimo se ubican en el extremo opuesto. El "vigor partidista» alude a la vida de los partidos políticos existente, medida por: la pluralidad de los mismos; la continuidad temporal de las formaciones partidistas; la atracción de una alta movilización electoral popular de apoyo y la gestación de subculturas políticas².

2. Chile, Argentina y Uruguay son ejemplos de máximo uvigor partidistan; Perí, Brasil, España, la anterior Checoslovaquia y Hungria se sitúan en un nivel intermedio, y Haití, Portugal, Rusia, Rumanía y Bulgaria en el mínimo. 
En el segundo de los escenarios tienen cabida, en primer término, el grado de movilización que logró conseguir la coalición social o polírica sobre la que se sostenía el régimen no democrático. Éste llegó a tener un amplio apoyo social en la base, con una fuerte alianza entre las elites políticas y sociales, en aquellos casos en que la sociedad estuvo fuertemente polarizada o cuando alcanzó el éxito a la hora de proveer resultados económicos favorables. En cuanto al nivel de la movilización popular, existen casos que dieron cabida al énfasis que se otorgó a la maximilización de la participación popular como otros referidos a una política contraria de desmovilización que llevó a provocar la exclusión. En segundo término, debe considerarse el tipo de institucionalización del régimen no democrático, puesto que los regímenes personales fueron muy diferentes de aquéllos donde existió un estilo de oligarquía consultiva, $y$, al mismo tiempo, la existencia de soluciones legales a las crisis periódicas políticas facilitó la acción de contraatacar el efecto de bloqueo del veto personal del dictador. Combinando la movilización y la institucionalización de los regímenes no democráticos se obtiene una nueva serie de casos que atienden bien a un nivel al to de ambas o a uno de perfil bajo ${ }^{3}$.

La unión de ambos escenarios, a efectos de establecer el "clima" previo de los partidos políticos antes de la transición, permite establecer un plano con los dos ejes conformados por el «vigor partidista" y por la combinación recién enunciada entre movilización e institucionalización que dan paso a los cuatro tipos siguientes: el cuadrante dominado por valores máximos de ambas variables se denomina de facilidad poliárquica, puesto que da cabida a sociedades que recogen tradiciones de partidismo democrático con alta capacidad movilizadora y una fuerte tendencia hacia la institucionalización expresamente formalizada ${ }^{4}$. En este espacio, el nuevo régimen democrático se ve conformado por sistemas de partidos fuertes, ampliamente presentes en la sociedad, con una gran capacidad intermediadora y catalizadores fundamentales de la vida política. El cuadrante dominado por los valores mínimos se define de imposibilidad poliárquica, siendo la tónica general la de la debilidad extrema, cuando no inexistencia, del sistema de parridos ${ }^{5}$. Los cuadrantes que conforman la diagonal transversal generan una situación dominada por la combinación de un alto "vigor partidista" con una reducida institucionalización y movilización, éste es el espacio intitulado proclividad poliárquica ${ }^{6}$; la política, sesgada por el déficit histórico institucional, adquiere caracteres personalistas que, sin embargo, se ve contrabalanceada por el sistema de partidos que desempeña un rol bastante activo en el nuevo régimen democrático. La forma opuesta o de difi-

3. El régimen chileno de Pinochet $y$ et de los países europeos del "socialismo real" conjugaron altas cotas de institucionalización y de movilización. Por el contrario, los regímenes militares argentino, boliviano, brasilcńo y uruguayo, y Haiti alcanzaron un nivel bajo. En un lugar incermedio se situaron los casos de Portugal, España, Paraguay y Perú.

4. El caso más neto es el de Chile.

5. El caso más evidente es el de Haití.

6. El caso nero lo conforman Argentina y Uruguay. 
cultad poliárquica ${ }^{7}$, contempla la escasa capacidad de un tradicionalmente débil sistema de partidos para neutralizar los liderazgos caudillistas que alcanzan ciertas cotas de institucionalización y de apoyo social.

\section{b) La crisis de apertura transicional}

El segundo elemento define una siruación peculiar que tiene que mantenerse en su forma analítica separada de la estrictamente referida a las transiciones a la democtacia política, porque el colapso de un régimen no democrático, sea autoritario o totalitario, puede o no crear las condiciones para el éxito del establecimiento de una democracia política (Linz, 1990: 144). No obstante, aquí se consideran la situación de agotamiento del anterior régimen político y la aparición de la estructura de oportunidades políticas que trae consigo un tipo de movilización social que se confronta con la oficialista en un momento de gran vulnerabilidad de ésta.

A los efectos de este trabajo, es el análisis de la estructura de oportunidades políticas, en cuanto que conlleva la movilización social que ocurre cuando un sistema cerrado comienza a abrirse, el más pertinente. Sus efectos hacen que aparezcan en el escenario un creciente flujo de presión sobre el régimen político a través de huelgas, manifestaciones, protestas generalizadas o el uso organizado de las instituciones gubernamentales ${ }^{8}$. El arranque de una oleada de movilizaciones puede contemplarse como una respuesta colectiva a la expansión generalizada de las oporrunidades políticas, en la que los costes y los riesgos de la acción colectiva son menguados y se incrementan las ganancias potenciales (Tarrow, 1991: 15). Como resuitado, aparecen en escena nuevos movimientos, entre los que el que tuviera más éxito podría llegar a institucionalizarse como partido político e incluso liderat el proceso de cambio?. Estos movimientos pueden ofrecer oportunidades a los ciudadanos para expresar $y$ expandir sus demandas e inmediatamente recogen a aquellos grupos que básicamente conforman organizaciones de disidentes. A medio y largo plazo stz capacidad de éxito, traducida en alcanzar el estadio de partidos políticos consolidados, se ve afectada por la ubicación del punto de partida según los cuadrantes anteriores y por el desarrollo de los dos elementos que se señalan más adelante. Sin embargo, existen casos en los que la estructura de oportunidades políticas apenas si operó, pudiéndose, por consiguiente, hablar en este apartado de situaciones "activas" o "pasivas" 10 .

7. Los casos necos son los de Rusia, Rumanía y Bulgaria.

8. La presión en las calles se dio en la mayoría de los paises de Europa central, especialmente en la República Democrática Alemana y en Rumanía, pero también acaeció en Uruguay y Brasil, donde las instituciones fueron más influenciables, mientras que el uso organizado de las instituciones oficiales ejerció presión en Chile.

9. Solidaridad y Carta 77 son, inicialmente, los más conocidos en este sentido.

10. Entre las "acsivas" se encuentran los casos de Chilc, Polonia y la anterior Checoslovaquia, mientras que entre las "pasivas" están España, Portugal, Paraguay y Rusia. Argentina, Uruguay y Hungría componen una situación intermedia. 


\section{c) La estrategia del cambio}

El tercer elemento asume un problema inicial que concierne a la definición de la propia estrategia del cambio. Desde la perspectiva de los partidos políticos, y entendiendo que asimismo son componentes de la estrategia las instituciones políticas existentes y el tipo de liderazgo, el cambio fue promovido por algún sector reformista de la clase dirigente no democrática; pero también fue capitaneado por líderes de la oposición que llenaron el vacío producido bien tras el colapso del régimen no democrático o como consecuencia de su propia acción de acoso. Con respecto a los pasos tomados, éstos podian ser de dos tipos: aquéllos que implicaban una reforma radical del tipo de régimen, y los que adoptaban las instituciones del último régimen democrático anterior. La primera de estas estrategias utilizaba una metodología similar, consistente en que las instituciones no democráticas se usaban por los actores democráticos bajo reglas electorales nuevas y que aseguraran plenamente la compecitividad del sistema, después las instituciones se transformaban "desde dentro" hacia una forma poliárquica. De nuevo se volvía a convocar unas elecciones para elegir a ciertos órganos del Estado y finalmente se promulgaba una nueva constitución "1. En esta circunstancia se originaba un sistema de partidos que tendian a reproducir el existente en el pasado preautoritario, reduciendo en gran medida el peso de las formaciones que apoyaron al régimen no democrático. Por el contrario, en el segundo caso, - aquél en el que los líderes democráticos opositores llegaron a dirigir la transición con exclusividad de otros actores-, se daba paso a un sistema nuevo de partidos al que se integraban, de forma decidida, los sectores más reformistas del régimen no democrático $y$, más tarde, algunos de los que conformaban la línea más dura del mismo; estos actores nuevos se caracterizaron por poseer una capacidad de negociación limitada debido a la falta de experiencia o a la debilidad en términos de genuino apoyo popular ${ }^{12}$. Con respecto a las inscituciones políticas de los regímenes no democráricos anteriores, cuando se usaron se hizo con eficiencia para alcanzar la transición polírica en la mayo-

11. Este fue el caso de España, Europa central, Brasil, Chile y Perú; mientras que el camino scguido por Argentina y Uruguay se basó en la aceptación, y uso, de la Constitución democrática anterior. Argentina y Uruguay, probablemente por haber sufrido periodos autotitarios no tan largos en comparación con los periodos en los que se vieron inmersos los orros países, conforman una excepción al argumento general aquí esgrimido.

12. Esto sucedió en España, Checoslovaquia y Hungría. En Polonia, Solidaridad apareció diez años antes de la quiebra del régimen no democrárico, como sucedió en Brasil con el surgimiento de fuerzas politicas durante el régimen militar. En Bulgaria y Rumania el cambio politico fue dirigido por el partido oficial del régimen anterior transformado, mientras que paulatinamente iba surgiendo una oposición minoritaria. Los casos restantes, durante sus procesos de transicion, tuvieron una elevada presencia de figuras sociales y polfticas tradicionales del período anterior al del régimen no democrático. El caso más exrremo, por el tiempo transcurrido, serfa el de Dolores Ibárruri, Pasionaria, en España, mientras que el de Fernando Belaúnde Terry y Vícror Raúl Haya de la Torre en Perú sería el ejemplo para los países latinoamericanos. 
ría de los $\operatorname{casos}^{13}$, debiéndose articular, como primera medida reformista, una legislación sobre partidos políticos que fuera no excluyente. Por último, el liderazgo, que también ha demostrado tener variados grados de significación en los procesos de transición estudiados ${ }^{14}$, asienta su impacto en el universo partidista en la capacidad de los líderes de conformar en su entorno maquinarias partidistas eficaces. De esta suerte, a los efectos de la existencia de sistemas de partidos consolidados, se constata una tendencia más desarrollada a correlacionar liderazgos de éxito en las transiciones llevadas a cabo con incapacidad de establecer partidos fuertes y duraderos ${ }^{15}$.

\section{d) El nuevo régimen democrático}

El cuarto elemento se encuentra bastante ligado al problema teórico del firal de una transición. Si se acepta que una transición finaliza cuando el nuevo régimen político comienza a funcionar después de un período de incertidumbre, esto conlleva que, bien los problemas tradicionales hubieran sido institucionalizados o procesados por el nuevo régimen ${ }^{16}$; o bien que las instituciones proveyeran la renovación de la elite política, total o parcial, confrontándose los gobernantes ante elecciones libres y competitivas ${ }^{17}$. En ambas situaciones, el papel de los partidos políticos era fundamental.

Por una parte, la propia aceptación de un escenario pluripartidista, así como la "desproscripción" de algunas fuerzas políticas, cuya marginación fue un recurso tradicional incluso en escenarios que se pretendfan democráricos, introducía de forma expresa una disyuntiva relevante ya abordada. De esta forma, existía la posibilidad de que la transición supusiese la restauración del sistema de partidos $o$, por el contrario, que diera paso a una situación de refundación. Pero, por otra parte, los partidos políticos iban a verse influidos de forma direc-

13. Excepto en Argenrina y Uruguay. Ahora bien, en algunos paises tales como España, Brasil y Chile estas instituciones hicieron que el cambio polftico se desarrollara más fácilmente. Así mismo, el inesperado colapso de Europa central y su tránsito hacia un sendero de pacífica democratización fue facilitado por el éxito de las instituciones comunistas.

14. España es el único caso en el que existe un líder prominente que une el régimen no democrático con el democrático. En Europa central, los lideres más relevantes aparecieron durante los años de oposición (Lech Walesa y Vaclav Havel). Sin embargo, con respecto a América latina, aunque la politica está fuertemente personalizada en la mayoria de los países, las transiciones no aporraron líderes incuestionables debido al papel de los partidos políicos tradicionales.

15. Los líderes del Movimiento de las Fuerzas Armadas de Porrugal, Adolfo Suárez, Lech Walesa, Vaclav Havel, Mijaíl Gorbachov y Boris Yelrsin han sido incapaces de articular dicho tipo de partidos.

16. Desde esta otra perspecriva, la ransición española termina tras "los juicios de Campamento" en 1982, la uruguaya en abril de 1989 después del referéndum sobre la Ley de Caducidad y la de la anterior Checoslovaquia en el momento que se esciden la República Checa y Eslovaquia en 1991.

17. Argentina tras las elecciones de 1985, Brasil en 1990, España en 1982, Perú en 1985, Chile en 1990 y Uruguay en 1989. Desde esta perspectiva, los paises de Europa central y del Esre se encuentran más atrasados. 
ta por dos de las opciones fundamentales tomadas a la hora de erigir los nuevos regímenes democráticos: la forma de gobierno y el sistema electoral elegidos. Integrando, de nuevo, en dos ejes de coordenadas las dos posiciones extremas de la forma de gobierno - presidencialismo y parlamentarismo-y de la fórmula de representación - sistema proporcional y sistema de pluralidad-. Los cuatro espacios definidos ${ }^{18}$ aportan uno que es el que acarrea peores consecuencias para la estabilidad de un sistema de partidos fuerte y operativo, como consecuencia de integrar dos lógicas dispares, aquélla regulada por opciones usuma cero" típica de la elección presidencial y la conformada por el utodos ganan" del sistema proporcional: la combinación de presidencialismo y de sistema proporcional. En el seno de los sistemas de partidos, la dificultad consiste en la necesidad de conjugar las necesarias "mayorías presidenciales» con la fragmentación de los mismos, fruto no sólo de la ley electoral sino de las propias divisiones existentes.

\section{Consideraciones para el caso centroamericano}

Antes de abordar la aplicación del modelo recién descrito al caso centroamericano conviene formular dos observaciones previas. La primera, de carácter formal, se refiere a la propia consideración de cuales son los países que van a ser objeto de referencia; en este sentido, las páginas que siguen van a centratse principalmente en El Salvador, Guatemala, Honduras y Nicaragua, todos los cuales han vivido un proceso de transición política a lo largo de los tres últimos lustros, pero también de Costa Rica, de cuya transición, si bien se produjo hace 45 años, pueden deducirse elementos interesantes. La segunda, de carácter substantivo, se refiere a la necesaria inclusión de un apartado más en el modelo explicativo absolutamente necesario en América Central; no es otra que la incidencia extrema de la política internacional en el marco cotidiano de la política.

Con respecto a la segunda de las observaciones, si bien la política de alguno de los países centroamericanos estuvo directamente impregnada por la presencia norteamericana en diferentes etapas de su historia ${ }^{19}$, la situación suscitada a finales de la década de 1970 supuso una escalada de internacionalización regional sin precedentes. En efecto, el triunfo revolucionario en Nicaragua en 1979 y los avances de la insurgencia en El Salvador y Guatemala compusieron un escenario que, paulatinamente, se fue integrando en el conflicto Este-Oeste. La presencia directa de actores norteamericanos y cubanos, así como el patro-

18. Parlamentarismo y sisrema proporcional (Portugal, España, la anrerior Checoslovaquia y Hungria); parlamentarismo y sistema de pluralidad; presidencialismo y sistema proporcional (Argentina, Chile, Uruguay, Brasil y Polonia), y presidencialismo y sistema de plutalidad.

19. Nicaragua fue invadida por los Estados Unidos en 1912 y sus marines permanecieron en el pais, salvo el paréntesis de 1925, hasta 1933, y en Honduras se sucedieron las intervenciones de los marines con frecuencia entre 1903 y 1925. En Guacemala, el golpe de estado contra Jacobo Arbenz de 1954 eservo inspirado y directamente animado por los Estados Unidos. 
cinio, material y moral, de las fuerzas en contienda por los polos extremos ideológicos, contribuyó notablemente a la internacionalización del conflicto $y$, por ende, a que cualquier solución al mismo estuviese sesgada por dicha situación. De esta manera, a los elementos del modelo antes añadidos habría que añadir un quinto que no se sumaría a sus cuatro precedentes sino que se superpondría a todos ellos incorporándoseles constantemente.

\section{a) El escenario internacional}

El tipo de dominación presente en América Central anterior a 1979 contaba con el apoyo explícito de los Estados Unidos. Esta circunstancia era muy significativa al constatar la clase de régimen imperante en El Salvador, Guatemala y Nicaragua que compatibilizaba una forzada parafernalia electoral sin ningún contenido real de que por su mediación se articularan las preferencias de la sociedad o existiera la posibilidad de elegir líderes políticos alternativos a los que detentaban el poder. Por otra parte, la existencia de un texto constitucional ni garantizaba la extensión de los derechos cívicos a la totalidad de la sociedad ni significaba la vigencia del imperio de la ley. Finalmente, el tipo de Fstado conformado tenía características sultanísticas cuando no cleptocráticas, toda vez que la élite gobernante dominaba el país bien mediante criterios de «negocio familiarn (Nicaragua), bien gracias a una sólida alianza entre la oligarquía agroexportadora y las fuerzas armadas (EI Salvador y Guatemala). En este entramado, los Estados Unidos se situaban confortablemente por cuanto sus interés "ístmicos" relativos a la seguridad del paso interoceánico y los intereses económicos de las inversiones de las empresas norteamericanas se encontraban a salvo.

La estabilidad de esta situación se mantenía gracias a la existencia de tres mecanismos: el control de las fuerzas armadas y la neutralización de raíz de cualquier veleidad nacionalista por la prepotente presencia de la Guardia Nacional formada por la propia Administración norteamericana o por la influencia directa en la política de formación militar y de suministro de equipo. El segundo mecanismo radicaba en el carácter proconsular de los embajadores norteamericanos en los países de la zona que se traducía en continuas intervenciones en la polírica nacional. Por último, el sobrepeso en la economia nacional del sector exportador confería al capital inversor norteamericano, en el terreno de la explotación y comercialización de los productos agrícolas, una presencia extraordinaria, tanto en la contabilidad nacional como en el mercado de trabajo, sin dejar de lado la propia estructura de los partidos políticos ${ }^{20}$.

Las fuerzas políticas presentes a partir de 1980 adoptaron en su marco de referencia, tanto ideológico como práctico, cual era su posición frente a los socios externos, gravitando decisivamente esta toma de postura en la estrategia

20. En Honduras, el juego tradicional de partidos entre el Partido Liberal y el Partido Nacional fue aprovechado y animado por las compañías fruteras norteamericanas Cuyamel Fruit y United Fruit Company, respectivamente. 
global del partido a seguir ${ }^{21}$. Por otra parte, la propia puesta en marcha de regímenes democráticos tuvo un carácter manifiesto de "imposición", de suerte que en Nicaragua se promovía la democracia "por intimidación" (Whitehead, 1991) con el consiguiente efecto en la propia dinámica partidista. El legado de la "era Reagan» tuvo, en este sentido, un impacto mucho mayor al de la presencia norteamericana de las décadas inmediatamente anteriores (Carothers, 1991; Morales, 1991, y Walker, 1987).

La internacionalización del proceso político centroamericano comportó, igualmente, dos consecuencias que tuvieron una incidencia directa en el ámbito partidista. La primera, derivada de la táctica guerrillera seguida por la izquierda, hizo que ésta articulara su discurso y su propuesta de organización futura de acuerdo con el modelo representado por la Revolución Cubana. Si bien es cierto que esta posibilidad no se plasmó, en términos estrictos, en la realidad posterior, el efecto demostración estuvo presente durante mucho tiempo ${ }^{22}$. No obstante, el influjo cubano incidió en la tendencia de la izquierda a no institucionalizarse según patrones poliárquicos y a caer en expresiones movimientistas.

La segunda consecuencia se refería a la presencia más activa de las familias partidistas internacionales europeas. Aunque la tradición socialdemócrata en América Central databa de tres décadas antes, ésta era muy reducida y se restringia en su actividad plena y continua a Costa Rica (Torres Rivas, 1993) ${ }^{23}$. Los procesos de transición de la década de 1980 precipitaron el patrocinio de fuerzas de la derecha moderada por parte de la democracia cristiana europea. De esta forma, la derecha costarricense se transformó en 1983 en el Partido Unidad Social Cristiano y aparecieron partidos democratacristianos en EI Salvador, Guatemala y Hondura ${ }^{24}$. En este apartado es interesante subrayar la coincidencia que hay entre el éxito, medido en términos electorales, de este tipo de partidos y la existencia de una estrategia contrainsurgente norteamericana. Podría esgrimirse la hipótesis de que su éxito a corto plazo es coyuntural debido al hecho de ser aceptados por un buen número de las partes

21. Un cjemplo a este respecto lo constituyó el cambio hacia una posición abiertamente pronorteamericana registrado en 1982 a cargo de Napoleón Duarte, que hizo que la Democracia Cristiana salvadoreña abandonara posturas anteriores críticas frente a Estados Unidos.

22. El caso del Frente Sandinista de Liberación Nacional fue el más próximo al modelo cubano, si bien hubo diferencias significativas como las derivadas de su caráceer no excluyente, así como de su propia composición heterogénea.

23. Bien es cierro que tanto Jacobo Arbenz como Guillermo Ungo estaban próximos al ideatio socialdemócrata, pero el gobierno de aquél quedó abortado por un golpe de estado y éste no tuvo acceso al poder por el fraude elcctoral en 1971 , circunstancias ambas que reducen a mero testimonio la presencia socialdemócrata en Guatemala y El Salvador respecrivamente hasta, al menos, la década de 1980.

24. Su impacto, en términos generales, fue elevado, toda vez que alcanzaron el poder cn tres de los cuatro paises: Cosra Rica, El Salvador y Guatemala. Si en Costa Rica ya habia un precedente de triunfo elecroral por una formación política bajo orro nombre, el éxito de Napoleón Duarte y de Vinicio Cerezo fue pionero y sirvió para dar una dimensión diferente a la política partidista centroamericana. 
implicadas como el «mal menom. De esta forma, una característica típica de los procesos de transición en América Central, como sería la emergencia de este tipo de partidos, aporta al entendimiento del nuevo sistema de partidos configurando un elemento más de inestabilidad e inconsistencia. Esto es, el dominio de aspectos coyunturales en la puesta en marcha de este tipo de partidos no contribuye a su asenramiento ni a la gestación de cuadros o militancia comprometida; tampoco ayuda a la generación de subculturas partidistas.

\section{b) Fundación frente a tradición partidista}

Cabe mantenerse que, a diferencia de los casos más estudiados del Cono Sur latinoamericano donde la tradición partidista ha sido un producto de los procesos transicionales (Cavarozzi y Garretón, 1989), en América Central ha predominado la figura de la fundación del sistema de partidos (Goodman y otros, 1990, y Booth y Seligson, 1989). Sin embargo, al aplicarse el modelo presentado en la primera parte para la década pasada en los casos de El Salvador, Guatemala, Honduras y Nicaragua y para 1948-1949 con relación a Costa Rica, se constata la existencia de los dos tipos de comportamiento en la subregión. Esto es, mientras que El Salvador, Guatemala y Nicaragua representan la fundación, Costa Rica y Honduras son la tradición partidista.

Antes de continuar, debe precisarse que, en este contexto, por fundación partidista se entiende la creación de un sistema de partidos nuevo como consecuencia de la aparición de divisiones; asi, se incorporan al sistema político en el entramado de los partidos no sólo nuevas formaciones de personalidad jurídica diferentes a las anteriores, sino también nuevas elites políticas y grupos sociales que abarcan un abanico ideológico mucho más amplio que el precedente. La tradición partidista comporta, contrariamente, la continuidad de las formas partidistas, de pautas de comportamiento y de las personas y demás instancias habitualmente integradas.

En los casos referidos a la fundación partidista se dan cita una situación de régimen autoritario previo de "imposibilidad poliárquica" como consecuencia de un "vigor partidista" muy reducido y de un grado de movilización relativo junto con un nivel de institucionalización inexistente. Este escenario contrasta vivamente con el que se da en los casos de tradición partidista cuya historia inmediata permite referirse a la "proclividad poliárquica".

En efecto, la debilidad histórica de los partidos políticos en El Salvador, Guatemala y Nicaragua ${ }^{25}$, y el repudio a la explícita organización de movilización popular procilive a los regímenes del momento, contrastan con Honduras y Costa Rica ${ }^{26}$ donde, en el primero de ellos, los partidos tienen una insólita

25. Incluso en el único periodo democrático del medio siglo posterior a 1930 que sólo se dio en Guaremala entre 1944 y 1954 no se pudo poner en marcha un siszema de pattidos minimamenze arriculado.

26. Una aproximación comparaiva a los casos de Costa Rica y de Honduras donde se recogen las diferencias más significativas se encuentra en Vega Carballo (1989). 
capacidad de camuflarse en las distintas coyunturas históricas del siglo XX. En Costa Rica, por su parte, las formaciones surgidas después de 1958 logran empalmar con la tradición de la década de 1940.

La estructura de oportunidades dio paso en El Salvador, Guatemala y Nicaragua a una situación "activa" de la que no era ajena la insurgencia guerrillera que, progresivamente, fue dando paso a frentes únicos. Además, en Nicaragua, las tensiones dentro de la propia burguesía con respecto al somocismo precipitaron la inclusión de sectores de la misma en la oposición. A lo largo del tiempo, y conforme se fueron sedimentando los conflictos, los frentes guerrilleros unificados se articularon en partidos políticos, aunque debido a la propia coyuntura esre proceso fue desigual en cada uno de los países ${ }^{27}$. Algo similar ocurrió en Costa Rica al transformarse, después de la guerra civil, el Frente de liberación Nacional en Partido de la I.beración Nacional. Contrariamente, en Honduras la situación tuvo un carácter "pasivo".

Con respecto al papel desempeñado por el liderazgo, debe constatarse la inexistencia de un liderazgo sólido e incuestionable en los distintos procesos de transición, a excepción del caso de José Figueres en Costa Rica. En este sentido, no puede constatarse la correlación entre liderazgos con éxito e incapacidad de establecer partidos fuertes y duraderos, dada la ausencia de aquéllos.

En cuanto al papel de los partidos después de la transición, si se acepta que su contribución debe recaer en "apuntalar y diseminar los valores y las normas adecuados al régimen político democrático... y asegurar la eficacia gubernamentaly (Rovira, 1993: 163), está lejos de articularse en una estrategia de consolidación. Problemas derivados de la existencia de una cultura política poco democrática y de la escasa tradición del juego partidista, unidos con los graves problemas existentes en la gobernación del Estado, hacen que el papel de los partidos en el nuevo estado de cosas sea reducido. Esta circunstancia, junto con otras relativas al funcionamiento del régimen político, hacen que el sistema democrático, salvo en el caso costarricense, apenas si se encuentre en vías de consolidación.

\section{c) Inestabilidad y pluripartidismo en los esquemas de fundacion}

Aunque el todavía escaso número de comicios celebrados desde 1982 no permite establecer un comportamiento de los resultados electorales definitivo, se constata que, en los países en los que se ha producido una fundación partidista, el peso de los partidos políticos es muy diferente si se comparan las elecciones presidenciales con las legislativas. Mientras que candidaruras presidenciales del mismo partido no han ganado dos ciras electorales sucesivas (salvo en EI Salvador: 1989 y 1994), en lo atinente a las elecciones legislativas, la disparidad en los resultados de los partidos de unas elecciones a otras mantiene algu-

27. Este es el proceso que convergió en la creación del Frente Sandinista de I.iberación Nacional en Nicaragua y dol Frence Farabundo Martí de Liberación Nacional en partido politico en El Salvador. 
nas constantes, aunque, bien es cierto, en Guatemala la izquierda no ha participado plenamente. Este hecho es una consecuencia de la combinación de la forma presidencialista de gobierno - en la que sólo gana uno-con el desgaste que sufre todo gobierno en épocas de crisis económica y de guerra. Pero, igualmente, es producto de la incapacidad de los partidos políticos de mantener clientelas mínimamente estables, llegando a descender, o aumentar, de unas elecciones a otras en veinte puntos porcentuales.

En el caso de la tradición partidista, la inestabilidad de los partidos, medida según el porcentaje de escaños que alcanzan en cada elección legislativa, es mucho menor. A to largo de ocho años, el Partido Liberación Nacional pasó del $58 \%$ al $51 \%$ y la oposición del $32 \%$ al $46 \%$; en idéntico periodo, en Honduras, el Partido Nacional pasó del $41 \%$ al $55 \%$ y su opositor del $54 \%$ al $43 \%$. Estas cifras chocan con las que reflejan el hundimiento de los partidos Demócrata Cristiano de Guatemala y El Salvador que pasan en cinco y seis años del $51 \%$

Tabla 1. Porcentajes de escaños obtenidos por los partidos politicos con representación parlamentaria.

\begin{tabular}{|c|c|c|c|c|c|}
\hline \multirow{2}{*}{$\begin{array}{l}\text { En Guatemala } \\
\text { Partido Demócrata Cristiano Guatemalteco } \\
\text { Unión del Centro Nacional } \\
\text { Partido Revolucionario } \\
\text { Movimiento de Liberación Nacional } \\
\text { Otros (4) }\end{array}$} & \multicolumn{3}{|c|}{ Elecciones de } & 1985 & 1990 \\
\hline & & & & $\begin{array}{l}1 \% \\
1 \% \\
2 \% \\
4 \%\end{array}$ & $\begin{array}{r}23 \% \\
35 \% \\
1 \% \\
3 \% \\
38 \%\end{array}$ \\
\hline En El Salvador & 1982 & 1985 & 1988 & 1991 & 1994 \\
\hline $\begin{array}{l}\text { Partido Democratacristiano } \\
\text { ARENA } \\
\text { Partido de Conciliación Nacional } \\
\text { Otros: } 1982 \text { y } 1985 \text { (2); } 1991 \text { y } 1994 \text { (3) }\end{array}$ & $\begin{array}{r}40 \% \\
32 \% \\
23 \% \\
5 \%\end{array}$ & $\begin{array}{l}55 \% \\
42 \% \\
3 \%\end{array}$ & $\begin{array}{l}37 \% \\
52 \% \\
11 \% \\
-\end{array}$ & $\begin{array}{l}31 \% \\
46 \% \\
11 \% \\
12 \%\end{array}$ & $\begin{array}{r}21 \% \\
46 \% \\
5 \% \\
28 \%\end{array}$ \\
\hline En Nicaragua & & Eleccio & es de 1 & 984 & 1990 \\
\hline $\begin{array}{l}\text { Frente Sandinista de Liberación Nacional } \\
\text { Unión Nacional Oposirora } \\
\text { Otros: } 1984 \text { (6); } 1991 \text { (2) }\end{array}$ & & & & $3 \%$ & $\begin{array}{r}42 \% \\
55 \% \\
3 \%\end{array}$ \\
\hline En Costa Rica & ones de & 1982 & 1986 & 1990 & 1994 \\
\hline $\begin{array}{l}\text { Partido de Libetación Nacional } \\
\text { P. U. Socialcristiano } \\
\text { Otros (3) }\end{array}$ & & $\begin{array}{l}58 \% \\
32 \% \\
10 \%\end{array}$ & $\begin{array}{r}51 \% \\
44 \% \\
5 \%\end{array}$ & $\begin{array}{r}44 \% \\
51 \% \\
5 \%\end{array}$ & $\begin{array}{r}51 \% \\
42 \% \\
7 \%\end{array}$ \\
\hline En Honduras & ones de & 1981 & 1985 & 1989 & 1993 \\
\hline $\begin{array}{l}\text { Partido Nacional } \\
\text { Partido Liberal } \\
\text { Otros: } 1981 \text { y } 1985 \text { (2); } 1989 \text { y } 1993 \text { (1) }\end{array}$ & & $\begin{array}{r}41 \% \\
54 \% \\
5 \%\end{array}$ & $\begin{array}{r}47 \% \\
50 \% \\
3 \%\end{array}$ & $\begin{array}{r}55 \% \\
44 \% \\
1 \%\end{array}$ & $\begin{array}{r}55 \% \\
43 \% \\
2 \%\end{array}$ \\
\hline
\end{tabular}


al $23 \%$ y del $55 \%$ al $21 \%$ respectivamente, o de los sandinistas: del $63 \%$ al $45 \%$ en seis años.

Una última característica correlaciona la fundación partidista con el pluripartidismo. Esto es, en Costa Rica y Honduras, países aquí definidos como de tradición partidista, el número de partidos presentes en el Legislativo no es en cualquiera de las tres últimas elecciones habidas en cada caso superior a cinco, concentrándose los escaños en los dos partidos más votados en un porcentaje comprendido entre el $90 \%$ y el $99 \%$ del total de los escaños. Contrariamente, en Guatemala el número de partidos presentes en el Legislativo es de ocho y los dos partidos mayoritarios nunca han cubierto más del $73 \%$ del total de los escaños; en El Salvador, el número de parridos ha sido de 3 a 6 y el porcentaje de los dos partidos mayoritarios sobre el total de escaños ha caído de estar situado entre el $87 \%$ y el $89 \%$ al 70\% tras las elecciones de 1994 que abrían el sistema de partidos al multipartidismo; finalmente, dadas las características de polarización de la vida política en Nicaragua, el pluripartidismo y la inestabilidad son una realidad en dicho país que ha quedado oculta en tomo a las dos posiciones de sandinismo-antisandinismo.

\section{Epílogo}

El estudio de las transiciones políticas, desde el punto de vista de los sistemas de partidos generados, ha puesto de relieve en qué medida las características de aquéllas pueden contribuir a crear nuevos sistemas de partidos o a revitalizar viejas formas de participación existentes en la sociedad. La presente ponencia ha tratado de plantear cómo, en el marco centroamericano, pueden suscitarse ambas situaciones. El escenario así reflejado ayuda, igualmente, a incorporar la discusión en torno a los partidos políticos en el ámbito más amplio que es el de la consolidación democrática.

La clave interpretativa, finalmente, viene a reclamar la forma en la que intervienen algunos de los elementos constitutivos de todo sistema político en perspectiva histórica. En este sentido, aspectos relativos a la cultura política, a las formas de dominación, al papel del Estado, al tipo y grado de participación sociopolítica, al estito del liderazgo y a la forma de gobierno, entre otros, tienen que ser tenidos en cuenta. No es menos ajena, en esta específica región, la variable internacional. 


\section{Bibliografía}

AICÁNIARA, Manuel (1992), «Las transiciones a ta democracia en España, América Latina y Europa Oriental. Elementos de aproximación a un estudio comparativon. Revista del Centro de Estudios Constitucionales, núm. 11, p. 9-42.

BoOT1, John A.; SELIGSON, Mitchell A. (ed.)(1989). Elections and Democracy in Central America. 'The University of North Carolina Press. Chapel Hill.

CaRothers, Thomas (1991). "The Reagan Years: The 1980s". En LoweNi"HAl., Abraham F. (ed.). Exporting Democracy. The United States and Latin America. Themes and Issues. Baltimore: The Johns Hopkins Universiry Ptess, p. 90-121.

Cavarozzi, Marcelo; Garreton, Manuel Antonio (Coord.) (1989). Muerte y resurrección. Los partidos politicos en el autoritarismo y las transiciones del Cono Sur. Chile: FLACSO.

GoOdman, Louis W; I.foGrande, William M.; MENDElson Forman, Johanna (ed.) (1990). Political Parties and Democracy in Central America. Westview Press. Boulder.

LINZ, Juan (1990). "Transiciones a la democracia». Revista Española de Investigaciones Sociologicas, núm. 51, p. 9-33. Madrid.

Morales (3., Abelardo (1991). "Scguridad y rigidez frente al cambio: la política de Fstados Unidos en Centroamérican. En VEREA CaMPOS, Mónica; BarRos HORCASITAS, José Luis (coord.). la politica exterior norteamericana hacia centroamérica. Reflexiones y perspectivas. México: Miguel Angel Porrúa, p. 37-58.

ROVIRA MAs, Jorge (1993). "Democracias emergentes y partidos políticos en Centroamérica: Consideraciones para su investigación». En STEICHEN, Régine (comp.). Democracia y democratización en Centroamérica. Costa Rica: Editorial de la Universidad de Costa Rica, p. 153-171.

TARROW, Sidney (1991). "Aiming at a moving target: Social science and the recent rebellions in Eastern Europe", Political Science \& Politics, XXIV, núm. 1, p. 12-19.

TORREs RIVAs, Edelberto (1993). "Personajes, idcologías y circunstancias: lo socialdemócrata en Centroamérican. En Vellinga, Menno (coord.). Democracta y polttica en América Latina. México: Siglo XXI.

VeGA CARBallo, José I uis (1989). "Partidos, desarrollo político y conflicto social en Honduras y Costa Rica. Análisis comparativo". Sintesis, núm. 8, p. 363-382. Madrid.

WAL,KER, Thomas W. (ed.)(1987). Reagan versus the Sandinistas. The Undeclared War on Nicaragua. Westview Press. Boulder.

WHITEHEAD, Laurence (1991). "The Imposicion of Democracy". En LOWENIHAL, Abraham F. (ed.). Exporting Democracy. The United States and Latin America. Themes and Issues. Baltimore: The Johns Hopkins University Press, p. 191-215. 